\title{
Alcaptonúria (ocronose)
}

\section{Alkaptonuria (ochronosis)}

Ricardo B. Cotias'; Gildásio C. Daltro ${ }^{2}$; Luiz Erlon A. Rodrigues ${ }^{3}$

\begin{tabular}{l|l}
\multicolumn{1}{c|}{ Unitermos } & resumo \\
Alcaptonúria & $\begin{array}{l}\text { A ocronose, manifestação clínica da alcaptonúria nos tecidos conectivos, geralmente leva a uma dege- } \\
\text { neração discal grave, com quadro radiológico exuberante e pouca sintomatologia, sendo o tratamento } \\
\text { Ocronose }\end{array}$ \\
Hérnia de disco & $\begin{array}{l}\text { cirúrgico raramente necessário. Este trabalho relata o caso de um paciente com ocronose que desen- } \\
\text { Lolveu uma radiculopatia em L5, à esquerda, secundária a hérnia discal paramediana esquerda, entre } \\
\text { por tratamento cirúrgico com discectomia isolada, e o resultado foi o desaparecimento dos sintomas } \\
\text { da radiculopatia em L5, sem recidiva nos } 26 \text { meses subseqüentes de acompanhamento. }\end{array}$
\end{tabular}

abstract

Ochronosis, alkaptonuric clinical presentation in connective tissues, often runs with severe disc degeneration. In these patients, symptoms and clinical signs of disc degeneration usually are not as prominent as might be expected from the extent of disease observed on X-ray, and discectomy is rarely needed. We report a case of disc herniation in an ochronotic patient with left L5 radiculopathy, with symptoms and clinical signs not responsive to 4-month physical therapy. Discectomy was performed, with sustained good results after a 26-month follow-up. key words

Alkaptonuria

Ochronosis

Disc herniation

\section{Introdução}

A alcaptonúria é uma doença hereditária e rara do metabolismo dos aminoácidos fenilalanina e tirosina, de caráter autossômico recessivo, causada pela mutação do gene HGD, que codifica a enzima homogentisato1,2-dioxigenase (EC 1.13.1.15) $)^{(10,18)}$. A diminuição da atividade dessa enzima, que se expressa principalmente no fígado e nos rins, é acompanhada pelo acúmulo do ácido homogentísico em diversos tecidos e por sua eliminação urinária(12).
O ácido homogentísico, em contato com o ar ou com o oxigênio dissolvido nos tecidos, é oxidado, formando um pigmento polimérico de coloração marrom-avermelhada conhecido como piomelanina ou alcaptona ${ }^{(15)}$.

O termo ocronose, cunhado há quase 150 anos, derivou-se do depósito de piomelaninanas nas cartilagens, emprestando-lhes uma coloração amarelada típica. Aliás, esse pigmento é depositado nos tecidos conectivos de olhos, orelhas, pele, tendões, válvulas car-

1. Médico-assistente e coordenador do Grupo de Cirurgia de Coluna do Hospital Universitário Professor Edgard Santos (HUPES); sócio-fundador do Instituto de Coluna da Bahia (INCOL).

2. Professor livre-docente; chefe do Serviço de Ortopedia e Traumatologia do HUPES, Faculdade de Medicina da Universidade Federal da Bahia (FAMED/UFBA).

3. Professor-titular de Patologia Clínica do Departamento de Apoio Diagnóstico e Terapêutico da FAMED/UFBA.

Trabalho realizado no Serviço de Ortopedia e Traumatologia do HUPES/FAMED/UFBA. 
díacas, cartilagens e ossos devido a sua alta afinidade com as fibrilas de colágeno, cercadas de mucopolissacarídeos, tal como ocorre na cartilagem hialina das grandes articulações periféricas e dos discos intervertebrais ${ }^{(5,6)}$.

A expectativa de vida nos pacientes alcaptonúricos é normal, apesar do acometimento precoce dos discos intervertebrais em $50 \%$ dos indivíduos, principalmente nos níveis torácico e lombar. Tipicamente, dores lombares intensas começam a ocorrer por volta dos 30 anos, acompanhadas de envolvimento de tendão-de-aquiles, válvulas aórtica e mitral, além de calcificações das artérias coronárias, presente em quase todos os pacientes após os 60 anos.

A artropatia se desenvolve por volta da quarta ou quinta década, em cerca de $30 \%$ dos pacientes, e progride com o avanço da idade. Apesar de o envolvimento vertebral ser comum, a sintomatologia geralmente não coincide com os achados radiológicos proeminentes e somente poucos necessitam de tratamento cirúrgico.

A provável ausência de citações na literatura médica brasileira de discectomia em pacientes alcaptonúricos foi o principal motivo da apresentação deste trabalho, que se refere a um caso de tratamento cirúrgico de hérnia discal lombar em paciente com ocronose suspeitada no préoperatório e confirmada com achado cirúrgico e exames laboratoriais.

\section{Relato de caso}

Paciente F.R.P.F, de 43 anos, sexo masculino, com queixa de dor lombar há mais de dois anos e aparecimento súbito de irradiação para membro inferior esquerdo associado a parestesia da face lateral da perna esquerda há quatro meses, sem melhora com tratamento fisioterápico, foi encaminhado ao ambulatório de cirurgia de coluna do Hospital Universitário Professor Edgard Santos da Universidade Federal da Bahia (UPES/UFBA).

Tinha como antecedentes médicos uma internação prévia, há seis meses, para tratamento de septicemia por Escherichia coli secundária a pielonefrite, em outra unidade hospitalar, e uma cirurgia para correção de ruptura do tendão-de-aquiles, há três anos. Ao exame físico apresentou rigidez e dor lombar, ausência de pigmentação em olhos, pele ou orelhas, com teste positivo da elevação da perna retificada, a $40^{\circ}$, no membro inferior esquerdo, associado a hipoestesia da face lateral da perna e do dorso do pé à esquerda. Força e reflexos normais. As radiografias da coluna lombar mostraram significativa diminuição de todos os espaços discais, com calcificação dos discos, esclerose dos platôs vertebrais e presença de pequenos osteófítos.

O estudo de imagem por ressonância magnética (RM) evidenciou calcificação dos discos intervertebrais e fenômeno de vácuo, degeneração dos platôs vertebrais, protrusão discal paramediana esquerda, entre L3 e L4 e mediana entre L5 e S1, sem evidências compressivas, além de uma hérnia paramediana esquerda entre $L 4$ e $L 5$, com sinais de compressão da raiz de L5 à esquerda.

A cintilografia óssea efetuada com tecnécio 99 metaestável (99mTc) evidenciou áreas de hipercaptação do radiotraçador na coluna torácica baixa e em toda a coluna lombar.

Foram indicadas e realizadas hemilaminectomia esquerda de L4-L5 e discectomia com ressecção de disco de coloração castanha, que descomprimiu a raiz de L5. O exame anatomopatológico evidenciou tecido cartilaginoso hialino contendo macrófagos que endocitaram pigmentos (Figura 1).

Após esses procedimentos, o paciente evoluiu com remissão completa do quadro álgico e da hipoestesia da face lateral de perna esquerda e foi acompanhado durante os 26 meses subseqüentes. Realizou RM de controle 22 meses após a cirurgia, não sendo evidenciadas novas hérnias discais.

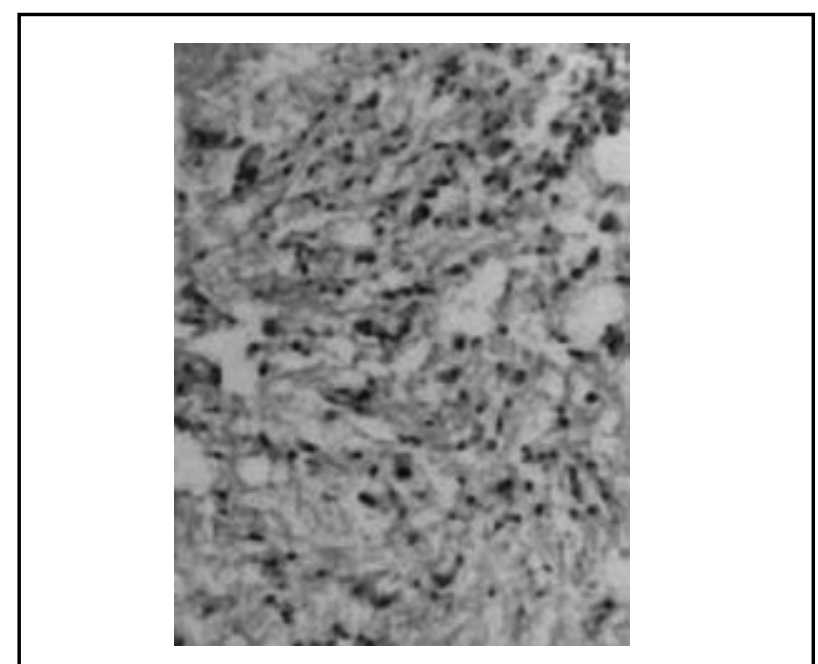

Figura 1 - Corte histológico de tecido fibrocartilaginoso discal corado pela hematoxilina/ eosina onde são notados macrófagos com pigmentos endocitados (H.E. 100 x)

\section{Teste de identificação da homogentisúria}

O ácido homogentísico é um agente redutor muito forte e que pode, por isso mesmo, ser detectado na urina usando-se reações de oxidorredução que produzem produtos 
coloridos, os quais podem ser mensurados espectrofotometricamente ${ }^{(1)}$.

No presente trabalho, o ácido homogentísico urinário foi qualitativamente detectado por meio da redução de solução de nitrato de prata amoniacal em banho-maria fervente ${ }^{(11)}$. Quanto maior o teor de ácido homogentísico na urina, mais intenso é o depósito a quente da prata metálica nas paredes internas do tubo de ensaio. Nesse caso, a homogentisúria foi tão intensa que resultou num enorme espelhamento das paredes do tubo (Figura 2). Esse achado não foi encontrado em uma amostra de controle.

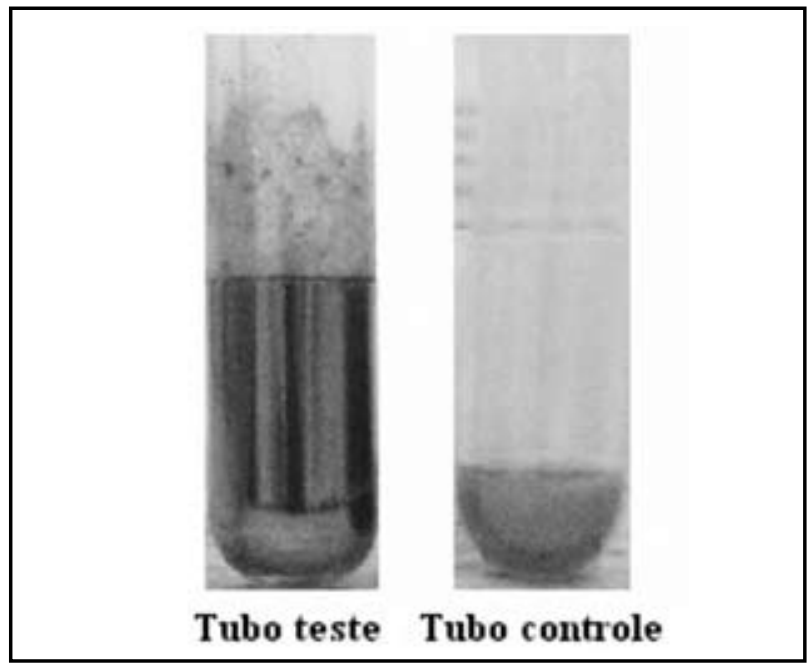

Figura 2 - Depósito de prata metálica (espelhamento) do tubo com a urina do paciente homogentisúrico

\section{Discussão}

A alcaptonúria é uma doença rara, com prevalência na maioria dos grupos étnicos estimada em 1:250 mil e em 1:19 mil na Eslováqia e na República Dominicana ${ }^{(9,19)}$. Foi descrita pela primeira vez por Scribonius, em 1854, em uma criança com urina escura. Boedeker e Virchow descreveram alguns casos em 1859 e 1866, e Aibrecht e Zdareck associaram a alcaptonúria com a ocronose em $1902^{(14)}$.

O ácido homogentísico originado do catabolismo oxidativo da L-fenilalanina e da L-tirosina é transformado, em todos os tecidos, em 4-maleil-acetoacetato, que é transformado em seu isômero 4-fumaril-acetoacetato, que por sua vez é clivado em ácido fumárico e acetoacetato, que são utilizados como fonte de energia pelas células ${ }^{(17)}$

A redução da atividade da enzima homogentisato dioxigenase (EC 1.13.11.5), decorrente de mutações no gene HGD, localizado no cromossomo 3q21-q23, leva ao acúmulo do ácido homogentísico em todos os tecidos ${ }^{(16)}$.

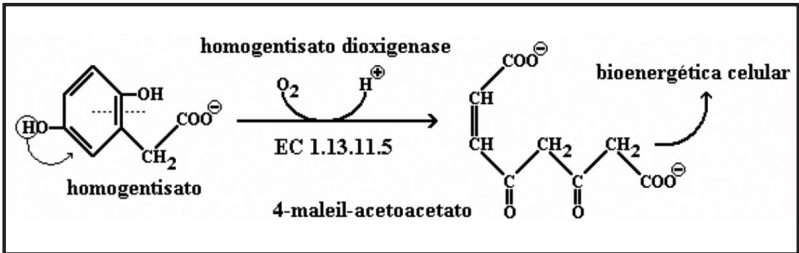

Figura 3

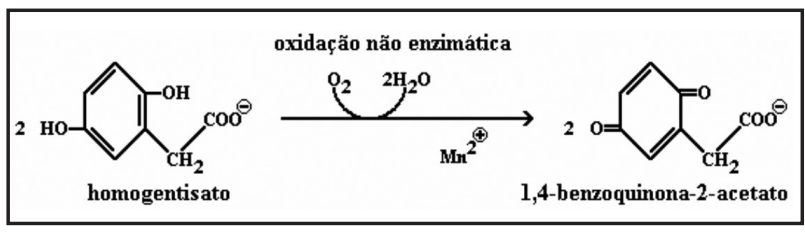

Figura 4

O aumento do teor de ácido homogentísico intracelular favorece sua oxidação, não-enzimática, para o seu derivado quinônico (1,4-benzoquinona-2-acetato), facilmente polimerizado na forma de uma mistura de pigmentos castanho-avermelhados, conhecidos como piomelaninas, característicos da ocronose.

Quase sempre os primeiros sintomas relacionados ao envolvimento articular dessa doença são rigidez lombar, dor lombar baixa em $60 \%$ dos casos $^{(4)}$ e ciática em $17 \%$ deles $^{(13)}$. Os pigmentos poliméricos decorrentes da oxidação do ácido homogentísico ligam-se, irreversivelmente, ao colágeno, e seus acúmulos nas cartilagens articulares e nos discos intervertebrais causam modificações da estrutura tissular, fragilizando-os(3). Essas alterações, que atingem principalmente a coluna lombar, podem levar à herniação do disco intervertebral. Além do envolvimento do disco e da cartilagem articular, existe também o dos tendões, que leva ao enfraquecimento e à ruptura espontânea ou decorrente de um trauma banal(2).

Apesar de a ruptura do disco ser comum, existem poucos relatos de tratamento cirúrgico de hérnia discal lombar em pacientes com ocronose. Em todos eles o diagnóstico foi feito após a cirurgia ${ }^{(7,8)}$. O caso, objeto deste trabalho, tinha antecedente de ruptura do tendão-de-aquiles, operado há três anos, e a sintomatologia era de compressão da raiz de L5 à esquerda, secundária à hérnia discal paramediana esquerda, entre L4 e L5. A associação desses sinais com as alterações radiográfícas de calcificação dos discos intervertebrais levou à suspeição de ocronose, a qual foi confirmada pela avaliação da homogentisúria.

Devido à ausência de melhora do quadro clínico, apesar do tratamento conservador por quatro meses, optou-se pela descompressão cirúrgica daquele único nível. A opção tomada mostrou-se acertada, uma vez que não houve recidiva dos 
sintomas após a cirurgia e até o último retorno do paciente, 26 meses depois. A RM para controle neste último encontro mostrou reabsorção das protrusões dos níveis de L3-L4 e L5-S1.
Apesar de ser uma doença rara, é importante lembrar da ocronose como causa de dor lombar, principalmente em pacientes na quarta ou quinta décadas de vida.

\section{Referências}

I. AL-ESSA, M. et al. Alkaptonuria: case report and review of literature. Ann Saudi Med, v. 18, n. 5, p. 442-4, 1998.

2.ANDO,W. et al. Bilateral Achilles tendon ruptures in patient with ochronosis. Clin Orthop Rel Res, v. 424, p. I80-2, 2004.

3. BALABAN, B. et al. Ochronotic spondyloarthropathy: spinal involvement resembling ankylosing spondylitis. Clin Rheumatol, v. 25, n. 4, p. 598-60I, 2006.

4. BORMAN, P.; BODUR, H.; CILIZ, D. Ochronotic arthropathy. Rheumatol Int, v. 2 I, p. 205-9, 2002.

5. CARREIRA, A.; FERREIRA, L. M.; LOUREIRO, V. Brown pigments produced by Yarrowia lipolytica. Result from extracellular accumulation of homogentisic acid. Appl Environ Microbiol, v. 67, n. 8, p. 3463-8, 200 I

6. COON, S. L. et al. Homogentisic acid is the product of MeIA, which mediates melanogenesis in the marine bacterium Shewanella colwelliana D. Appl Environ Microbiol, v. 60, n. 8, p. 3006-10, 1994.

7. EMEL, E. et al.Alkaptonuria with lumbar disc herniation: A report of two cases. Spine, v. 25, n. 16, p. 214|-4, 2000.

8. FARZANNIA, A.; SHOKOUHI, G.; HADIDCHI, S. Alkaptonuria and lumbar disc herniation. Report of three cases. J Neurosurg, v. 98, n. I, p. 87-9, 2003.

9. FISHER, A. A.; DAVIS, M.W. Alkaptonuric ochronosis with aortic valve and joint replacements and femoral fracture A case report and literature review. Clin Med Res, v. 2, n. 4, p. 209I5, 2004.

I0. JANOCHA, S. et al. The human gene for alkaptonuria (AKU) maps to chromosome 3q. Genomics, v. 19, n. I, p. 5-8, 1994.

I I. KACHMAR, J. F. Proteins and aminoacids. In: TIETZ, N. W. Fundamentals of clinical chemistry. Philadelphia:W. B Saunders Company, 1970. p. 177-82.

12. KAZANCIOGLU, R. et al. Alkaptonuria and renal failure. J Nephrol, v. 17, p. 44I-5, 2004.

13. KELLER, J. M. et al. New developments in ochronosis: review of literature. Reumatol Int, v. 25, p. 8I-5, 2005.

14. KOOPMAN,W..;; MORELAND, L.W. Arthritis and allied conditions: a textbook of Rheumatology. 14. ed. Lippincott: Williams \& Wilkins, 200I.

15. KOTOB, S. L. et al. Homogentisic acid is the primary precursor of melanin synthesis in Vibrio cholerae, a Hyphomonas strain and Shewanella colwelliana. Appl Environ Microbiol, v. 6I, n. 4, p. $1620-2,1995$.

16. MONTAGUTELLI, $X$. et al. Aku, a mutation of the mouse homologous to human alkaptonuria maps to chromosome 16. Genomics, n. 19, p. 9-1 I, 1994.

17. MORAN, G.R. 4-hydroxyphenylpiruvate dioxygenase. Arch Biochem Biophys, v. 433, p. I 17-28, 2005.

I8. RODRÍGUEZ, J. M. et al. Structural and functional analysis of mutations in alkaptonuria. Hum Mol Gen, v. 9, n. I 5, p. 234 I50, 2000.

19. ZATKOVA, A. et al. Rapid detection methods for five HGO gene mutation causing alkaptonuria. Clin Genet, v. 63, p. |45-9, 2003. 